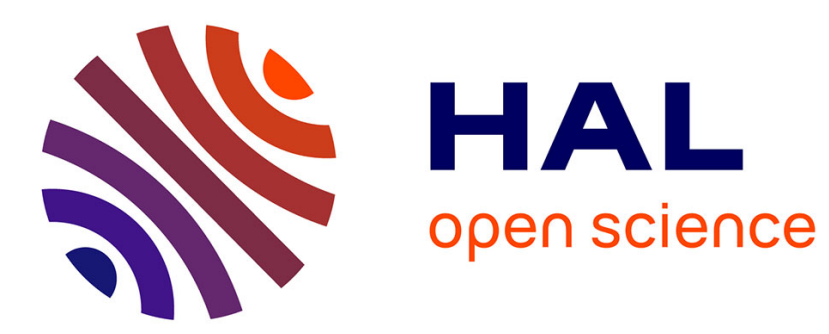

\title{
Ferrite bead effect on Class-D amplifier audio quality
}

Kevin El Haddad, Roberto Mrad, Florent Morel, Gaël Pillonnet, Christian

Vollaire, Angelo Nagari

\section{To cite this version:}

Kevin El Haddad, Roberto Mrad, Florent Morel, Gaël Pillonnet, Christian Vollaire, et al.. Ferrite bead effect on Class-D amplifier audio quality. 17th IEEE MELECON, Apr 2014, Beyrouth, Lebanon. 10.1109/MELCON.2014.6820510 . hal-01103584

\section{HAL Id: hal-01103584 \\ https://hal.science/hal-01103584}

Submitted on 15 Jan 2015

HAL is a multi-disciplinary open access archive for the deposit and dissemination of scientific research documents, whether they are published or not. The documents may come from teaching and research institutions in France or abroad, or from public or private research centers.
L'archive ouverte pluridisciplinaire HAL, est destinée au dépôt et à la diffusion de documents scientifiques de niveau recherche, publiés ou non, émanant des établissements d'enseignement et de recherche français ou étrangers, des laboratoires publics ou privés. 


\title{
Ferrite Bead Effect on \\ Class-D Amplifier Audio Quality
}

\author{
Kevin El Haddad ${ }^{* \S}$, Roberto Mrad ${ }^{* \dagger \ddagger}$, Florent Morel ${ }^{\dagger}$, Gael Pillonnet ${ }^{\ddagger}$, Christian Vollaire ${ }^{\dagger}$ and, Angelo Nagari* \\ * Analog, MEMS and Sensors (AMS) Group, \\ ST Microelectronics, Grenoble, France \\ firstname.lastname@st.com \\ †University of Lyon, Ecole Centrale de Lyon \\ Ampere, CNRS UMR5005, 36 avenue Guy de Collongue, 69134 Ecully, France \\ firstname.lastname@ec-lyon.fr \\ $\ddagger$ University of Lyon, CPE \\ INL, CNRS UMR5270, 43 bd de 11 Novembre 1918, 69616 Villeurbanne, France \\ firstname.1astname@cpe.fr \\ §Plateforme de Recherche en Nanosciences et Nanotechnologies \\ Lebanese University, Campus Fanar, 90656 Jdeidet, Lebanon
}

\begin{abstract}
This paper studies the effect of ferrite beads on the audio quality of Class-D audio amplifiers. This latter is a switching circuit which creates high frequency harmonics. Generally, a filter is used at the amplifier output for the sake of electromagnetic compatibility (EMC). So often, in integrated solutions, this filter contains ferrite beads which are magnetic components and present nonlinear behavior. Time domain measurements and their equivalence in frequency domain are presented. Total Harmonic Distortion (THD) measurements according to the audio signal frequency and amplitude are exposed and discussed. It is shown that ferrite beads introduce up to $30 d B$ of additional THD which prove the negative effect of the ferrite bead on the amplifier audio quality.
\end{abstract}

Index Terms-Ferrite bead, Magnetic material, Audio frequency band, Harmonics distortion

\section{INTRODUCTION}

The work exposed in this paper is dedicated to the audio systems of embedded applications. For such devices, the energy is provided by a battery and is then limited. Therefore, for a longer battery life, managing the energy distributed among all parts of this device, in the most efficient way, is a need. Concerning specifically the audio application, nowadays Class-D amplifiers combine high power efficiency and low audio distortion. Its power efficiency can reach $95 \%$ while for other classes, the power efficiency cannot exceed $75 \%$ [1]. Mainly for this reason, the Class-D is widely used in hands free applications [2]. The Class-D amplifiers, having a similar topology as a buck converter, are switching circuits controlled by a pulse width modulation (PWM) as shown in Fig. 1. The audio signal is compared to a triangular signal with higher frequency which can be in the range of [48 $\mathrm{kHz}-1 \mathrm{MHz}$ ]. This generates the PWM signal that controls the switching

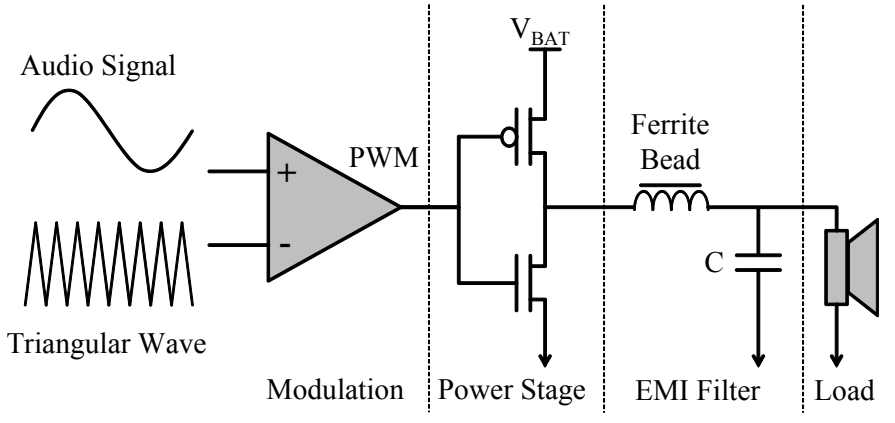

Fig. 1. Basic architecture of Class-D audio amplifier.

power stage. Fig. 2 shows the amplifier output spectrum for a given audio signal. The audio signal is a $10 \mathrm{kHz}$ sinusoidal wave, the fundamental switching frequency is $420 \mathrm{kHz}$ and the harmonics are spread all over the frequency band [3]-[5].

This amplifier can therefore, be a source of electromagnetic interference (EMI) and then disturb surrounding electronic devices. Thus, an EMI filter is required to eliminate the high frequency harmonics. In mobile phones and integrated applications, ferrite beads are used in EMI filters for their impedance characteristics and their broadband effect [6]. The ferrite bead impedance behavior allows a wide range filtering effect compared to an inductor. In addition, the ferrite bead dissipates the high frequency disturbance into heat due to its resistive behavior at high frequencies [6].

By neglecting the nonlinear behavior of magnetic materials, the impedance of the ferrite bead can be resumed to a 


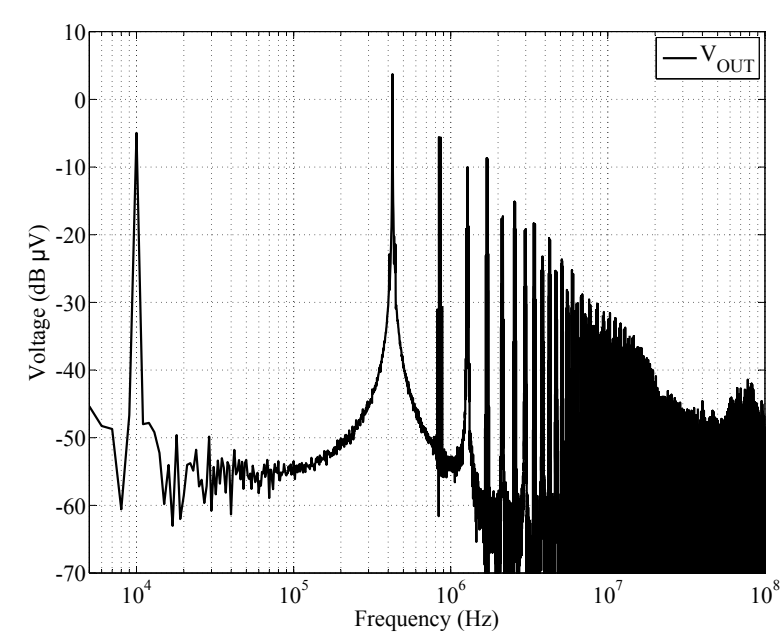

Fig. 2. Class-D amplifier output signal in the frequency domain.

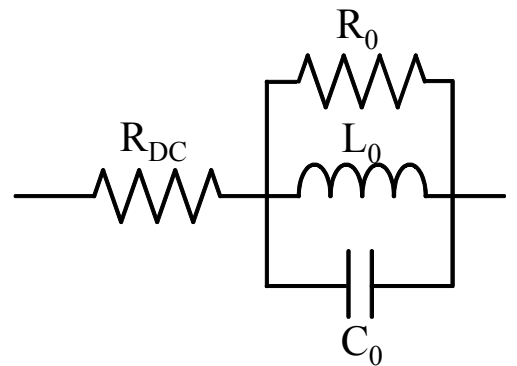

Fig. 3. Ferrite bead common model.

linear equation. Therefore, the ferrite bead low signal level impedance behavior with respect to the frequency has already been defined in the literature and used in many types of simulation [7]-[9]. These model are in general obtained by impedance fitting using the impedance measurement on the component. This lead to the most common ferrite bead models (see Fig. 3) which are composed by linear resistors, inductors and capacitors. Often they are provided by the ferrite bead suppliers as well.

However, a ferrite bead is made of magnetic materials, thus, it has nonlinear effects due to the hysteresis loop and the magnetic saturation [10]. In audio applications, nonlinear behavior has an impact on the signal audio quality [11]. The ferrite bead can, thus, contribute to deteriorate the signal audio quality provided by the power amplifier.

Since the aforementioned model do not take into account the ferrite bead nonlinearities, no simulations can be done that study the effect of an EMI filter including a ferrite bead on the audio reproduction chain. In addition, by the authors best knowledge, no publications have been found that study such phenomenon. Therefore, this paper presents some experimental measurements in order to expose the ferrite bead behavior in the audio band and quantify these effects on an audio amplifier's performance.

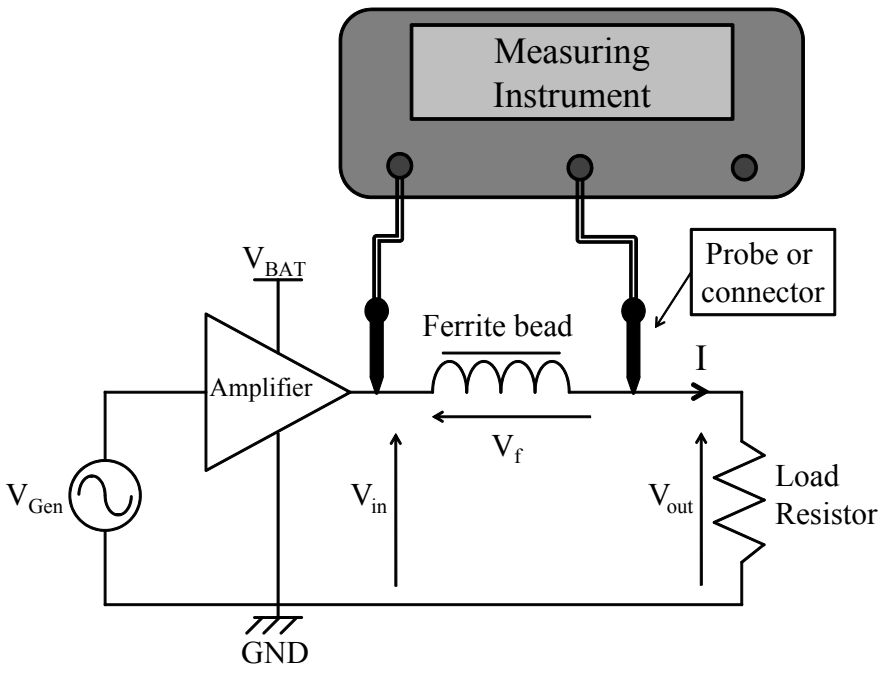

Fig. 4. Circuit schematic.

In section II, time domain measurements of the voltage across the ferrite bead are exposed to show the nonlinear characteristics of the ferrite bead. In section III, the equivalence of time domain measurements in the frequency domain are shown to evaluate their effect in the audio band. Section IV exposes total harmonic distortion (THD) measurements with respect to the signal amplitude level and to the frequency. Finally, section V concludes the paper.

\section{Time Domain Measurements}

This section shows time domain measurements on a simplified circuit containing a ferrite bead.

\section{A. Bench description}

Fig. 4 shows the circuit schematic used to measure the voltage delivered by the power amplifier $\left(V_{i n}\right)$ and the voltage across the load (i.e., loudspeaker) $\left(V_{\text {out }}\right)$. The circuit contains a ferrite bead in series with a linear amplifier (voltage gain $0 \mathrm{~dB}$ ) and a load of $8 \Omega$ (similar to the DC resistance of the loudspeaker). A ferrite bead with a rated current of $50 \mathrm{~mA}$, a DC resistor of $1.5 \Omega$ and $0.6 \mathrm{~mm} \times 0.3 \mathrm{~mm}$ dimensions. A linear amplifier is used rather than a class-D amplifier. This choice allows to remove the high frequencies effect of a PWM class-D signal and focus only on the effect of a ferrite bead in the audio band. The measurements were made using a 12bit digital oscilloscope which is represented by the measuring instrument in Fig. 4.

To avoid increasing the temperature of the ferrite bead and therefore changing its internal resistance, the signal applied at the input of the amplifier was burst pulses of five periods of a $1 \mathrm{kHz}$ sinusoidal signal. Pulses were separated by a delay of one second. The voltage across the ferrite bead is then the difference between $V_{\text {in }}$ and $V_{\text {out }}$.

\section{B. Measurement}

Fig. 5 shows the measurement on $V_{\text {in }}$ and $V_{\text {out }}$ in the time domain. Fig. 5 shows as well a zoom on both voltages near to 


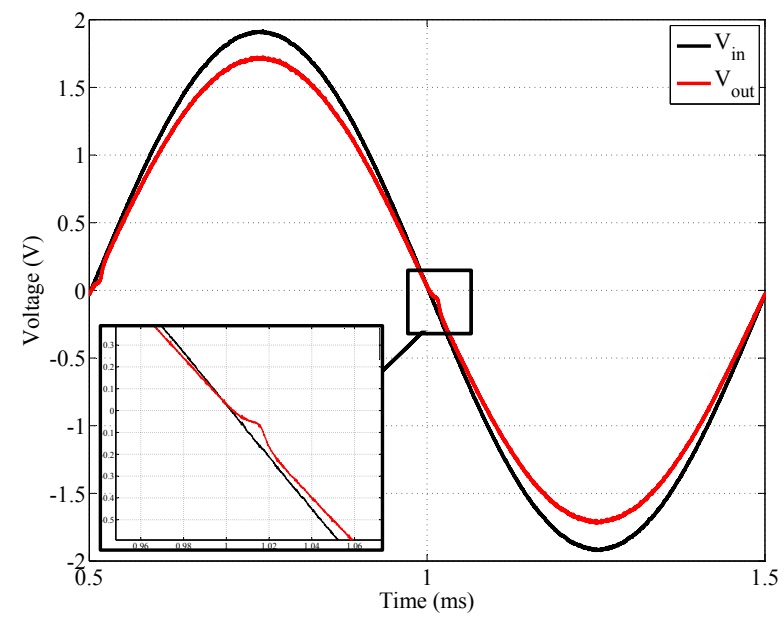

Fig. 5. Time domain measurement of $V_{\text {in }}$ and $V_{\text {out }}$.

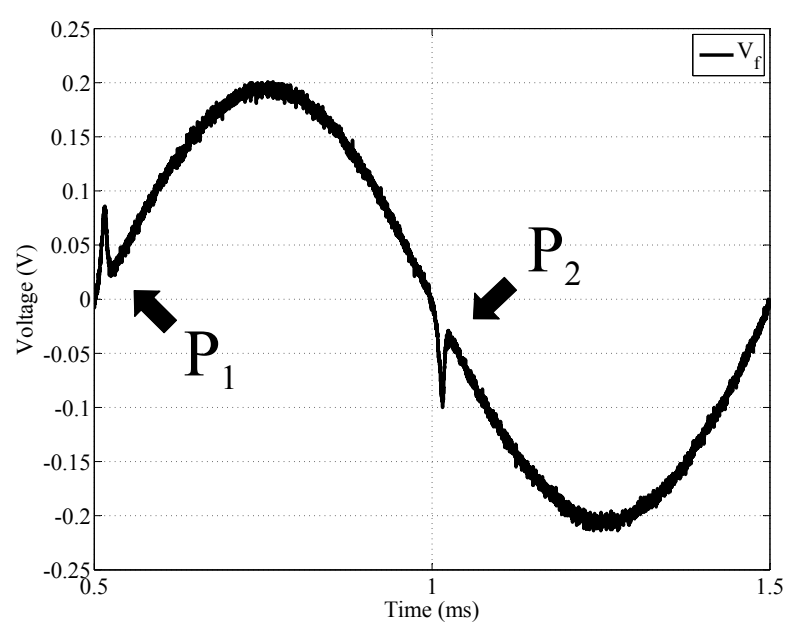

Fig. 6. Voltage across the ferrite bead.

their zero level. It can be seen that voltage measured before the ferrite bead $V_{\text {in }}$ keeps it's sinusoidal nature. However, The voltage measured after the ferrite bead, presents some nonlinear behavior near to zero. According to (??), the voltage across the ferrite bead is computed and shown in Fig. 6.

As can be seen in Fig. 6, pikes appear when the signal passes through $0 \mathrm{~V}$. This can be explained by considering the relationship of the voltage across the ferrite bead to the magnetic flux density (1) and the relationship of the ferrite bead current to the magnetic field (2)

$$
\begin{gathered}
B(t)=\frac{1}{N S} \int\left[v_{f}(t)-R_{D C} i_{f}(t)\right] d t \\
H(t)=\frac{N}{l} i_{f}(t)
\end{gathered}
$$

where $v_{f}$ is the ferrite bead voltage, $i_{f}$ is the ferrite bead current, $N$ the turn number of the coil, $l$ the effective length,

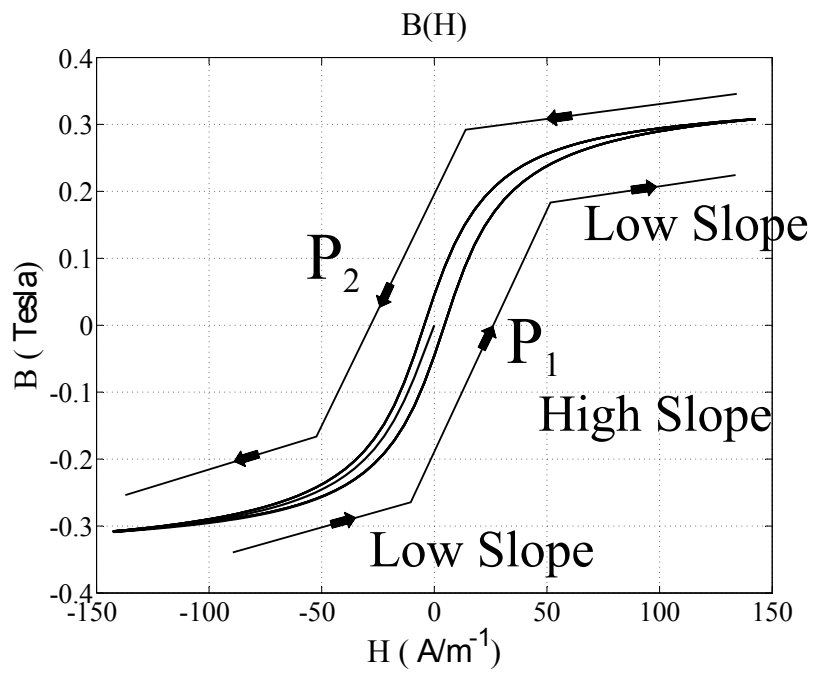

Fig. 7. Magnetic hysteresis loop.

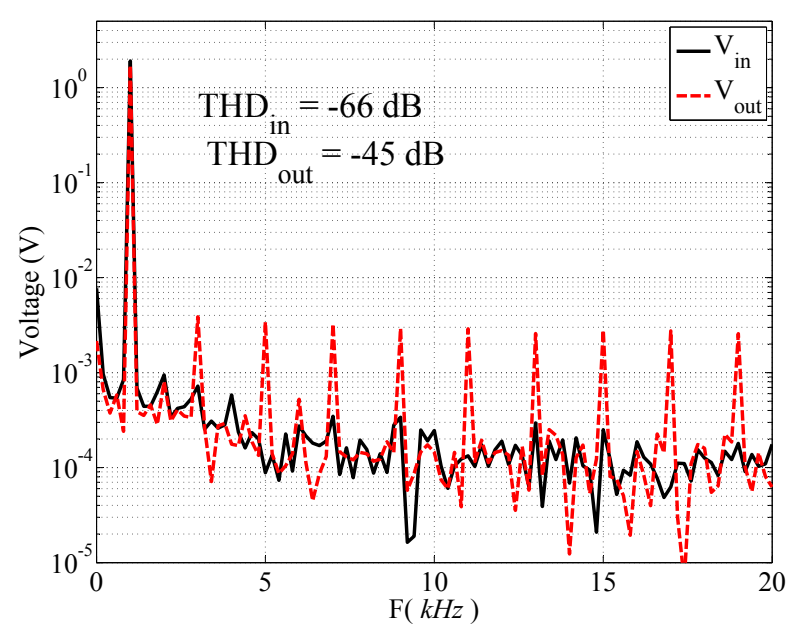

Fig. 8. Effect of the ferrite bead in the audio frequency band.

$S$ the section area of the magnetic material, $B$ the flux density, $H$ the magnetic field and $t$ is the time. A fast variation of B, which means a high slope in Fig. 7, happens at $H$ zero crossing and therefore at the $i$ zero crossing (since $i$ and $H$ are proportional). This induces the fast variation of $v_{f}$ which creates voltage peaks at the zero crossing parts denoted by $P_{1}$ and $P_{2}$ in Fig. 6.

\section{FREQUENCY DOMAIN ANALYSIS}

The Fast Fourier Transform (FFT) was applied on $V_{i n}$ and $V_{\text {out }}$ to transform the time domain signals into the frequency domain. Fig. 8 shows the frequency domain results of both voltages.

As seen in Fig. 8, the voltage across the load $V_{\text {out }}$ is affected by the nonlinear behavior of the ferrite bead. The impact appears as odd harmonics in the audio band which can be 
explained by the fact that the hysteresis loop is symmetric around zero [12].

By definition, the increase of the harmonics implies an increase of the THD. This latter is the ratio of the harmonic power sum over the fundamental power for a given signal. It is used to quantify the signal linearity. A low or a high THD would mean respectively a good or a bad linearity of the signal. In the audio applications, the THD is used to evaluate the efficiency of a given system to reconstitute the original audio signal. In this case, only the harmonics in the audio frequency band $([20 \mathrm{~Hz}-20 \mathrm{kHz}])$ are taken into account. The next section will therefore show THD measurements with respect to the signal frequency and to the signal amplitude levels.

\section{THD MEASUREMENTS}

In this section, the total harmonic distortion is measured to quantify the impact of the ferrite bead on the signal audio quality.

The THD was measured using an audio analyzer to study the effect of the ferrite bead on the signal linearity. Thus, measurement for different signal amplitudes and signal frequencies have been made. Note that, each measurement point uses 9 harmonics for THD measurements.

The circuit schematic used to measure the THD is the same as the one described in Fig. 5. The only differences are: first, the measuring instrument is an audio analyzer instead of an oscilloscope, second, a ferrite bead having a rated current of $2 A$ and a DC resistor of $50 \mathrm{~m} \Omega$ is used. This ferrite bead is chosen for these measurement because generally, for industrial applications, ferrite beads with high rated current and low DC resistors are used. Thus, it is possible to quantify the THD in real use case.

Fig. 9 and Fig. 10 show the THD measurements according to the signal amplitude and signal frequency respectively. In Fig. 9, the measurements were done using a $1 \mathrm{kHz}$ sinusoidal signal, sweeping the amplitude level from $1 \mathrm{mV}$ to $7 \mathrm{~V}$. In Fig. 10, the measurements were done using a $200 \mathrm{mV}$ sinusoidal signal with a frequency sweep from $20 \mathrm{~Hz}$ to $10 \mathrm{kHz}$. Note that Fig. 10 shows measurements up to $10 \mathrm{kHz}$ only, since all the harmonics become out of band when the signal frequency exceeds $10 \mathrm{kHz}$.

In Fig. 9 and Fig. 10, TH $D_{G e n}$ is the THD of the original signal delivered by the generator. $T H D_{\text {OpenCircuit }}$ is the THD at the output of the amplifier when it's operating in open circuit (no current is delivered). $T H D_{\text {in }}$ and $T H D_{\text {out }}$ are respectively the THD for $V_{\text {in }}$ and $V_{\text {out }}$ (see Fig. 4). $T H D_{\text {in }}$ represents the THD of the linear amplifier when delivering a current to the load. $T H D_{\text {out }}$ represents the THD across the load voltage. Therefore, the difference between $T H D_{i n}$ and $T H D_{\text {out }}$ is due to the ferrite bead.

As can be seen from Fig. 9, the ferrite bead deteriorates the signal THD in the amplitude range $[10 \mathrm{mV}-7 \mathrm{~V}]$. Ferrite beads have a negative impact on the audio signals even though the component current in the range of $[1 m A-737 m A]$ is lower than the component rated current which is $2 A$. However, below $10 \mathrm{mV}$ the amplifier output noise does not allow any

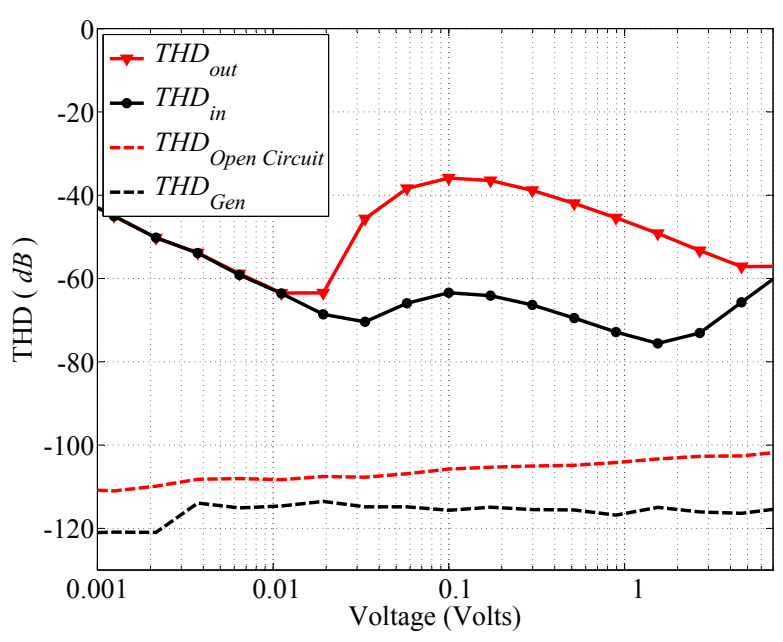

Fig. 9. THD measurements according to the signal amplitude.

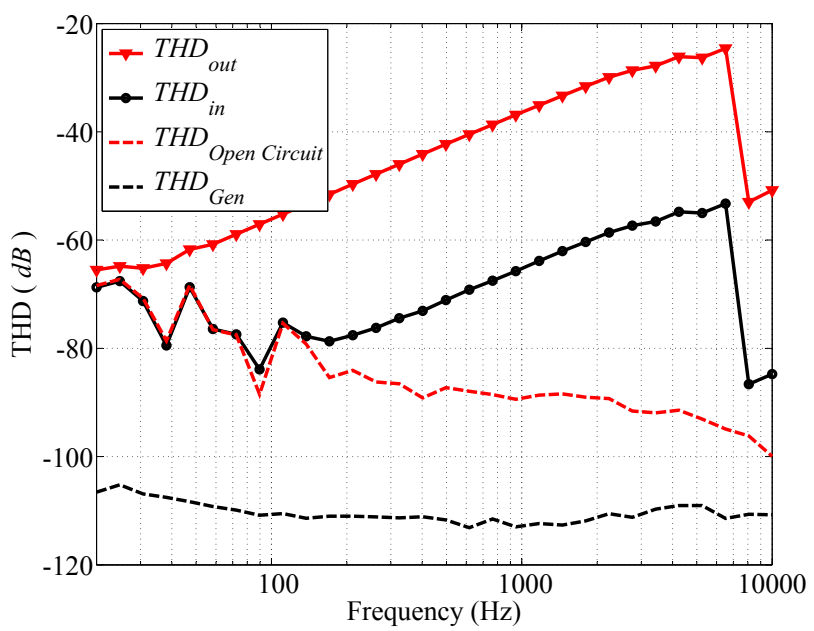

Fig. 10. THD measurements according to signal frequency.

comparison. Moreover, Fig. 10 shows that the ferrite bead increases the THD on the entire frequency range. Note that, beyond $6.5 \mathrm{kHz}$ the THD measurements decrease suddenly. This is because some of the odd harmonics are already out of the audio band.

As a result, the ferrite bead increases the THD of the signal delivered by the amplifier at all frequencies and a wide range of signal levels. The deterioration caused by the ferrite bead can reach $-35 d B$. Note that, $-40 d B$ of THD level can be distinguished by the human ear. Thus, the ferrite bead reduces the audio quality of the amplifier due to its nonlinear effect in the audio band.

\section{CONClusion}

This paper showed that ferrite beads used for EMI suppression in Class-D amplifier systems, have a non-negligible effect on the amplifier audio quality. In the time domain, the ferrite 
bead nonlinear behavior is seen as peaks apparition at voltage zero crossing. This can be translated to the frequency domain by an increase of the odd harmonics in the audio frequency band.

Furthermore, the THD measurements showed the impact of the ferrite bead on the audio quality for all the tested frequencies and a wide range of signal amplitudes. The THD measurements and FFT calculations proved, therefore, the significant impact of these non-linearities on the audio performance.

This paper highlights the need of a model taking into account the ferrite bead non-linear behavior, to help the designers choose their optimal ferrite bead.

\section{REFERENCES}

[1] E. Gaalaas, "Class D Audio Amplifiers: What, Why, and How," in Analog Dialogue, Jun. 2006.

[2] M. Berkhout, "Class-D audio amplifiers in mobile applications," in Circuits and Systems, 2009. ISCAS 2009. IEEE International Symposium on, may 2009, pp. $1169-1172$.

[3] R. Cellier, E. Allier, A. Nagari, C. Crippa, R. Bassoli, G. Pillonnet, and N. Abouchi, "A fully differential digital input class d with emi spreading method for mobile application," in Audio Engineering Society Conference: 37th International Conference: Class D Audio Amplification, Aug 2009. [Online]. Available: http://www.aes.org/elib/browse.cfm?elib=15226
[4] R. Mrad, F. Morel, G. Pillonnet, C. Vollaire, P. Lombard, and A. Nagari, "N-conductor passive circuit modeling for power converter current prediction and EMI aspect," Electromagnetic Compatibility, IEEE Transactions on, vol. 55, no. 6, pp. 1169-1177, 2013.

[5] R. Mrad, F. Morel, G. Pillonnet, C. Vollaire, and A. Nagari, "Integrated class-D audio amplifier virtual test for output EMI filter performance," in Ph.D. Research in Microelectronics and Electronics (PRIME), 2013 9th Conference on, 2013, pp. 73-76.

[6] C. Burket, "All ferrite beads are not created equal - understanding the importance of ferrite bead material behavior," In Compliance Magazine, 2010.

[7] J. Urabe, K. Fujii, Y. Dowaki, Y. Jito, Y. Matsumoto, and A. Sugiura, "A method for measuring the characteristics of an EMI suppression ferrite core," Electromagnetic Compatibility, IEEE Transactions on, vol. 48, no. 4, pp. 774-780, 2006.

[8] J. Urabe, K. Fujii, A. Harun, Y. Matsumoto, and A. Sugiura, "A study of EMI suppression characteristics of ferrite cores," in Electromagnetic Compatibility, 2006. EMC-Zurich 2006. 17th International Zurich Symposium on, 2006, pp. 622-625.

[9] C. Rostamzadeh, F. Grassi, and F. Kashefi, "Modeling SMT ferrite beads for SPICE simulation," in Electromagnetic Compatibility (EMC), 2011 IEEE International Symposium on, 2011, pp. 530-535.

[10] G. R. Skutt, "High-frequency dimensional effects in ferrite core magnetic devices," 1996, virginia Polytechnic Institute and State University.

[11] A. Knott, T. Stegenborg-Andersen, O. C. Thomsen, D. Bortis, J. W. Kolar, G. Pfaffinger, and M. A. E. Andersen, "Modeling distortion effects in class-d amplifier filter inductors," in Audio Engineering Society Convention 128, May 2010. [Online]. Available: http://www.aes.org/e-lib/browse.cfm?elib=15294

[12] Bob Metzler, Audio Measurement Handbook, ser. Audio Precision, January 2005 